\title{
Design of a Hybrid Photovoltaic Thermal System in Lebanon
}

\author{
Elie Karam, Patrick Moukarzel, Maya Chamoun, Charbel Habchi and Charbel Bou-Mosleh* \\ Mechanical Engineering Department \\ Faculty of Engineering, Notre Dame University-Louaize \\ Zouk Mosbeh, Lebanon \\ * Corresponding author: cboumosleh@ndu.edu.lb
}

\begin{abstract}
Due to global warming and the high toxic gas emissions of traditional power generation methods, renewable energy has become a very active topic in many applications. This study focuses on one versatile type of solar energy: Hybrid Photovoltaic Thermal System (hybrid PV/T). Hybrid PV/T combines both PV and thermal application and by doing this the efficiency of the system will increase by taking advantage of the temperature loss from PV module. The solar radiation and heat will be harnessed to deliver electricity and hot water simultaneously. In the present study a solar system is designed to recycle the heat and improve the temperature loss from PV module in order to supply both electricity and domestic hot water. The project was tested twice in Zouk Mosbeh - Lebanon; on May 18, 2016, and June 7, 2016. The average electrical efficiency was around $11.5 \%$ with an average electrical power output of 174.22 W, while with cooling, the average electrical efficiency reaches $11 \%$ with a power output of $200 \mathrm{~W}$. The temperature increases by about 7 degrees Celsius from the inlet. The 1D conduction model is also performed in order to design the hybrid PV/T system.
\end{abstract}

Keywords-renewable energy; hybrid; photovoltaic; heat transfer; efficiency.

\section{INTRODUCTION}

There are two types of solar panels that collect Sun's light and heat: solar water heating panels and photovoltaic solar panels Solar water heaters, also known as solar domestic hot water systems, use solar radiation in order to heat water for domestic or residential applications. Photovoltaic Solar Panels convert sunlight into electricity. The main desire of the researchers was to develop cells that have a low cost and a high efficiency [1]. The problem with photovoltaic panels is that their efficiency drops with temperature increase at a rate about $0.4-0.5 \%$ per $1{ }^{\circ} \mathrm{C}$ once the baseline temperature of $25^{\circ} \mathrm{C}$ has been exceeded [2]. Several methods have been developed in order to limit the efficiency drop of PV panels by cooling them.

Recent study shows that the solar panel can attain a gain of 8 to $9 \%$ of net energy by pumping water over the surface of the panel. This continuous flow of water acts as a cooling method for the cells and a cleaning agent that reduces panel soiling [2].
Bojanampati et al. [3] experimentally investigated both air and water forced cooling methods. Their work made use of a Plexiglas U-channel which was in direct contact with the PV modules so as to remove thermal contact resistance. At an illuminance of 22 flux, the peak power output increase was $10 \%$ from passive to forced air cooling, $48 \%$ when water at $21^{\circ} \mathrm{C}$ was used, and $66 \%$ when chilled water at $14^{\circ} \mathrm{C}$ was used. Mehrotra et al. [4] investigated the effects of PV module emersion in water on its efficiency. It was reported that the efficiency of the panel increased with immersion depth up to a certain point, after which the efficiency began to decline. The maximum efficiency of $4.76 \%$ was obtained under $1 \mathrm{~cm}$ depth of water with the proposed design and operating condition.

The objective of this study is to design a solar system that recycles the heat and improves the temperature loss from PV module in order to supply electricity and domestic hot water.

\section{PROTOTYPE IMPLEMENTATION}

The copper tube piping network design was chosen to be a parallel pipe system rather than a serpentine pipe system as shown in Figure 1. The parallel riser tubes are designed to transport collector fluid from the bottom of the collector to the top. The headers have a larger diameter than the risers because fluid pressure is greatest at the base at the incoming fluid and least by the output pipe, so the pressure difference is moderate and the flowrate in each of the parallel pipes is more uniform. The flowrate is minimal at the center of the collector due to its smaller diameter where most of the heat is concentrated. An insulation cover is used on the back of the panel to reduce the heat losses to ambient air.

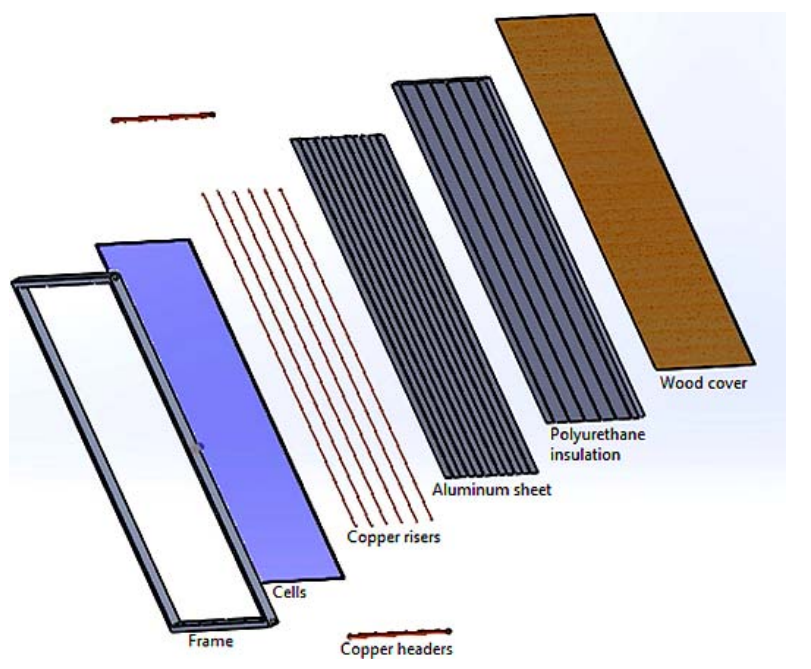

Figure 1: The different parts of the PV/T system 
The pump is selected based on the head and the flow rate. The flow rate is assumed to be equal to $0.8 \mathrm{GPM}$ and the head should be equal to the head loss of the system. The total head loss is equal to the summation of minor and major losses due to the fittings and the pipe equal to $4 \mathrm{~cm}$.

The 1D thermal resistance network model is used to determine a convenient polyurethane insulation thickness for the back of the PV/T as shown in Figure 2. First the heat is lost from the water to the inner riser walls by convection. Then the heat loss is conducted to the ambient air through several conducting media [5]. Two assumptions are made here: the water average bulk temperature is $40^{\circ} \mathrm{C}$ and the ambient air temperature is $25^{\circ} \mathrm{C}$. The calculation shows that an insulation thickness of $6.5 \mathrm{~mm}$ is needed for the prototype.

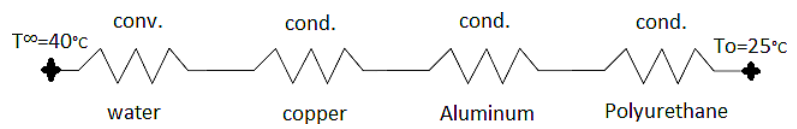

Figure 2: Thermal resistance network

\section{EXPERIMENTAL STUDY}

The system was tested twice, the first time on Wednesday May 18, 2016, and then on June 6 and 7 2016. Figure 3 shows a schematic diagram of the system. The setup shown in Figure 4 consists of the hybrid PV/T panel, insulated PEX pipes, a 60 $\mathrm{L}$ tank, $12 \mathrm{~V}$ DC pump and $12 \mathrm{~V}$ battery, a pyranometer to measure the solar irradiance, flowmeter, voltmeter, digital thermometer, thermocouple, six 12V LED lamps each rated at $50 \mathrm{~W}$, and a multimeter. The panel was oriented with an inclination of $33^{\circ}$ to the south due to the solar positioning consideration.

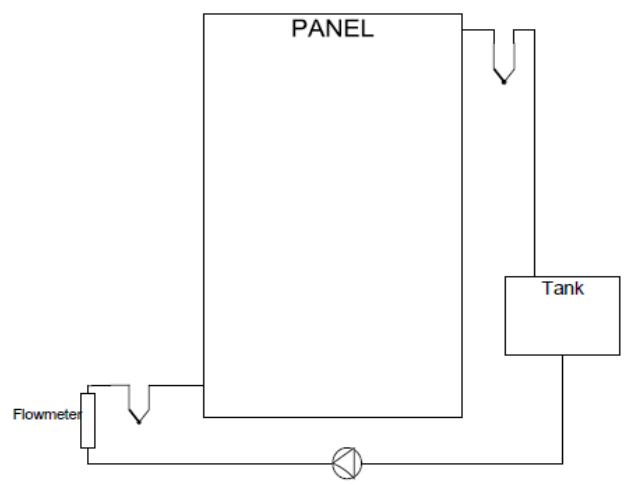

Figure 3: Schematic diagram of the system

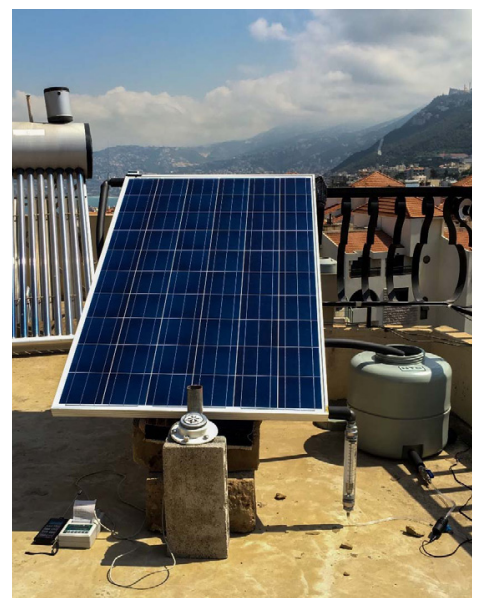

Figure 4: The experimental setup

Figure 5 shows the panel and fluid temporal temperature variation. It is observed that the panel temperature is around $49^{\circ} \mathrm{C}$ in May and around $56^{\circ} \mathrm{C}$ in June due to higher ambient air temperature in the later. The temperature difference in May is better than that obtained in June due to higher solar irradiance as shown later. In May the average temperature difference is around $5.4^{\circ} \mathrm{C}$ with a maximum of $8^{\circ} \mathrm{C}$. The temperature difference in June drops to $3.3^{\circ} \mathrm{C}$ with a maximum around $5^{\circ} \mathrm{C}$.

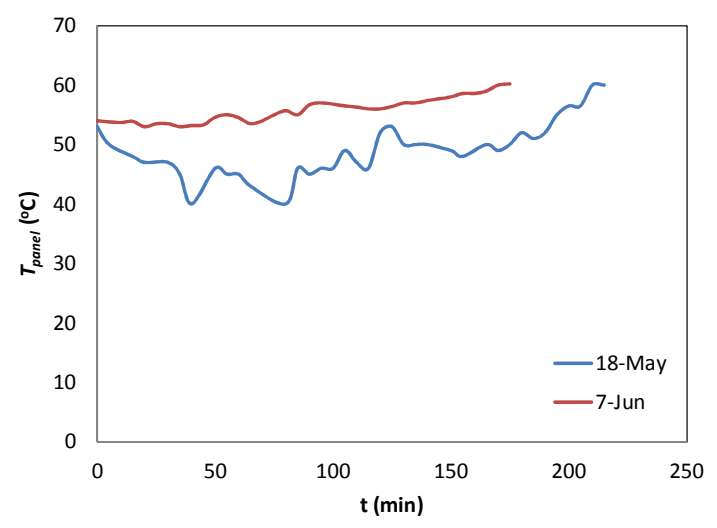

(a)

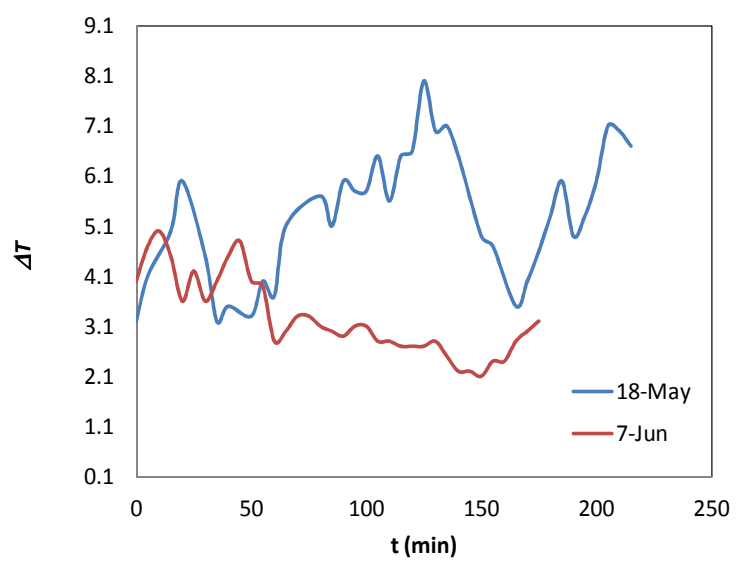

(b)

Figure 5: Temporal variation of the (a) panel temperature and (b) temperature difference between the inlet and the outlet 
The thermal energy can be evaluated using the following equation:

$$
E_{\text {thermal }}=\dot{m} c_{p} \Delta T
$$

where $\Delta T$ is the temperature increase from the inlet to the outlet.

Knowing the dimensions of the panel the input power could be calculated as follows:

$$
P_{\text {in }}=G \times A
$$

with $G$ the solar irradiance in $\mathrm{W} / \mathrm{m}^{2}$, and the area of the panel is $A=1.626 \mathrm{~m}^{2}$.

The output power is obtained as follows:

$$
P_{\text {out }}=V \times I
$$

where $V$ and $I$ are the measured voltage and current output, respectively.

The electrical efficiency can be evaluated using the following equation.

$$
\eta_{\text {ele }}=\frac{P_{\text {out }}}{P_{\text {in }}}
$$

The thermal efficiency can be evaluated using the following equation.

$$
\eta_{\text {th }}=\frac{E_{\text {thermal }}}{P_{\text {in }}}
$$

Figure 6 shows the temporal variation of the thermal energy and input and output power. Figure 7 shows the temporal variation of the thermal and electrical efficiency. The average input power in May is around $1720 \mathrm{~W}$ while in June it drops to $1606 \mathrm{~W}$ with a decrease of around $6.6 \%$ explaining the results presented in the previous paragraph. For the output electrical power, the average is around $200 \mathrm{~W}$ for the experiment done in May while in June it drops to $182 \mathrm{~W}$. It should be noted that the oscillations in the results were due the passing clouds which blocked the sun thus decreasing the irradiance. The average thermal power output evaluated using equation (1) is around $1408 \mathrm{~W}$ in May and $861 \mathrm{~W}$ for June. This is caused by the low temperature difference obtained in June relative to that obtained in May as shown earlier.

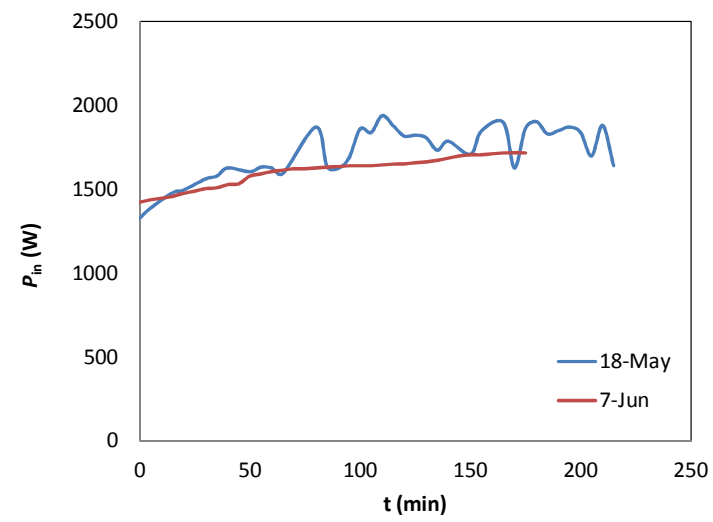

(a)
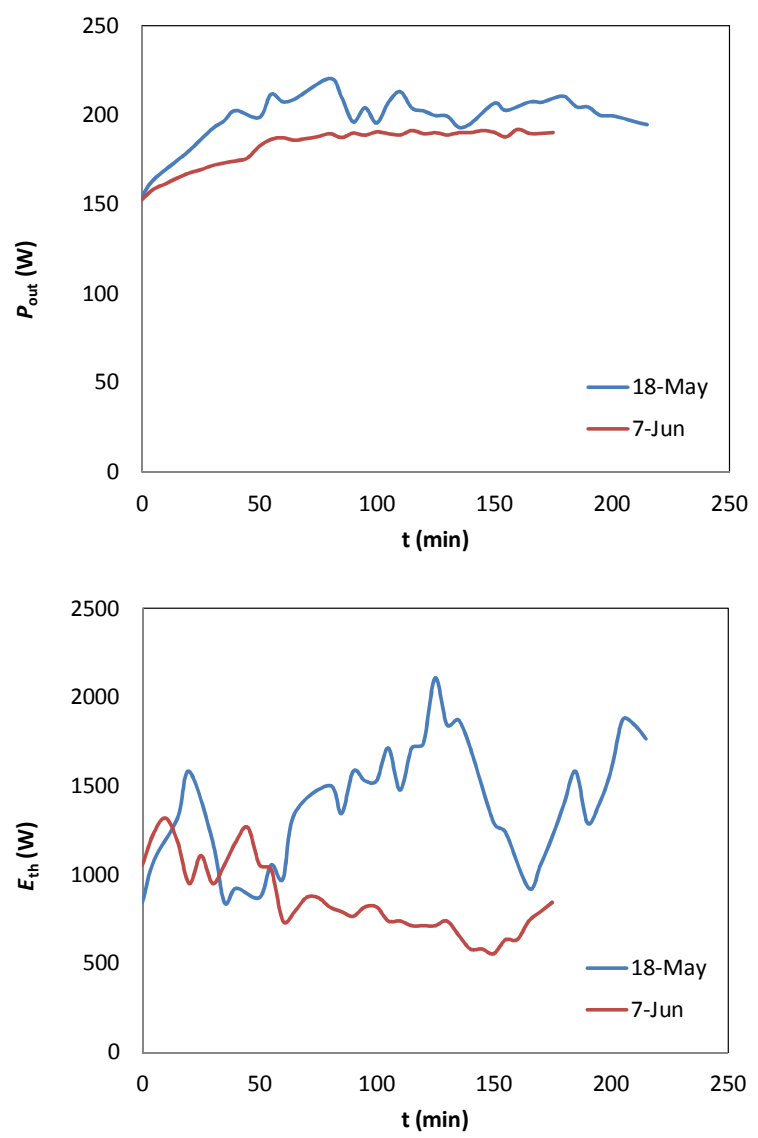

(c)

Figure 6: Temporal variation of (a) input power, (b) output electrical power and (c) thermal power

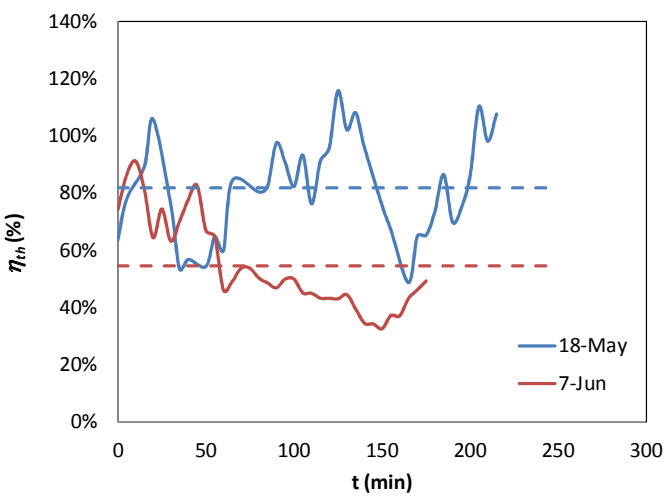

(a)

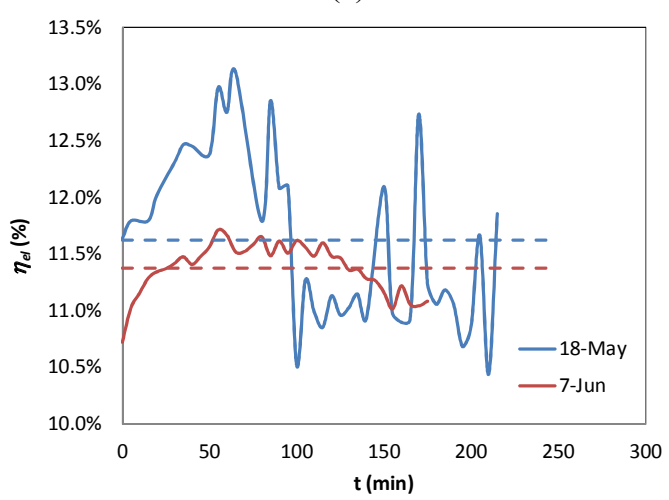

(b)

Figure 7: Temporal variation of the (a) thermal and (b) electrical efficiency 
Figure 8 shows the variation of electrical efficiency in June for the case with and without cooling. As it can be observed from this figure, the cooling process enhances the efficiency of the PV panel by about $0.5 \%$.

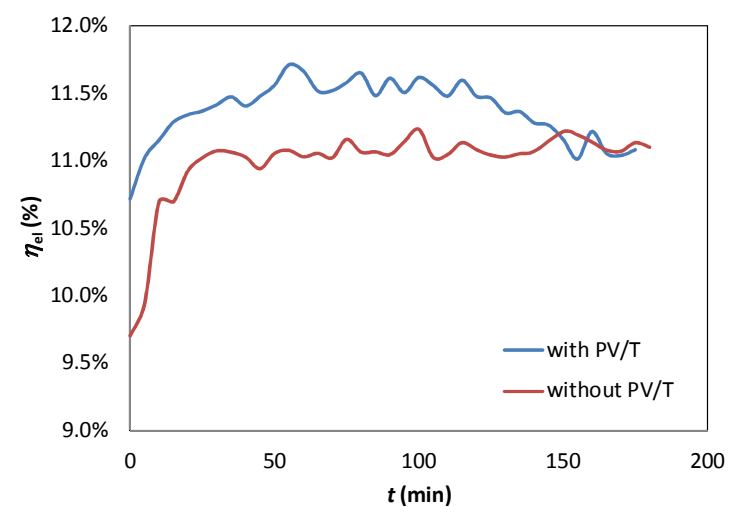

Figure 8: Temporal variation of the electrical efficiency in June for the cases with and without cooling

\section{CONCLUSION}

The main objective of this study was to design and test a method to cool the photovoltaic cells with circulating water, and also take advantage of the heated water for domestic use. Hence, the efficiency of the panel will increase, and the circulating water will be hot enough for domestic use. The project was tested twice; on May 18, 2016, and June 7, 2016 in Lebanon.

An average of $11.5 \%$ electrical efficiency was achieved and an $82 \%$ average thermal efficiency on the first testing and $54 \%$ on the second one. The temperature difference between the inlet and the outlet reaches around $5.4^{\circ} \mathrm{C}$ for May and $3.3^{\circ} \mathrm{C}$ in June. The average electrical power calculated was around $200 \mathrm{~W}$. The second testing was done to be able to compare the electrical efficiency with and without cooling. The average electrical efficiency without cooling was $11 \%$, while an average of $11.5 \%$ with was achieved with cooling.

The electrical efficiency of the system did not increase as much as it was intended since the panel temperature did not reach the baseline of $25^{\circ} \mathrm{C}$, but water was heated enough to be used in domestic applications. If the panel temperature was to be dropped to reach almost $25^{\circ} \mathrm{C}$, chilled water could be used, but this will take more time to heat it.

Therefore, Hybrid PV/T harnesses the solar radiation and combines both PV and thermal application to deliver electricity and hot water simultaneously.

Finally, the results obtained so far in this project should encourage local and global sectors to think about alternative green power generation methods in order to decrease global warming and the high toxic gas emissions of traditional power generation.

\section{REFERENCES}

[1] J. Andrews and N. Jelley, Energy sience: principles, technologies, and impacts, Oxford University Press, United Kingdom, 2013.

[2] M. K. Smith, H. Selbak, C. C. Wamser, N. U. Day, M. Krieske, D.J. Sailor, and T.N. Rosenstiel, "Water cooling method to improve the performance of field-mounted, insulated, and concentrating photovoltaic modules," Journal of Solar Energy Engineering. Vol. 136(3), pp. 034503-1-4, January 2014. doi: 10.1115/1.4026466.

[3] S. Bojanampati, P. Rodgers, and V. Eveloy, "Experimental assessment of flat-type photovoltaic module thermal behavior," Proeedings of the 13th International Conference on Thermal, Mechanical and MultiPhysics Simulation and Experiments in Microelectronics and Microsystems (EuroSimE), , April 16-18, 2012. doi: 10.1109/ESimE.2012.6191695.

[4] S. Mehrotra, P. Rawat, M. Debbarma, and K. Sudhakar, "Performance of a solar panel with water immersion cooling technique," International Journal of Science, Environment and Technology, Vol. (3), pp. 11611172, June 2014.

[5] J. H. Lienhard IV and J. H.Lienhard, A heat transfer textbook, Phlogiston Press, Cambridge, Massachusetts, USA, 2008. 